*Doutora em Direito PPGD/ UFSC. Mestre em Direito e Relações Internacionais PPGD/ UFSC. Professora na Faculdade de Direito e no Programa de PósGraduação em Direito (Mestrado) da Universidade de Passo Fundo/ RS.E-mail: patriciagnoschang@ gmail.com

**Advogada, bacharel em Direito pela Universidade de Caxias do Sul, Especialista em Direito do Trabalho Contemporâneo, Processo do Trabalho, Direito Previdenciário e Prática Previdenciária pela Universidade de Passo Fundo. E-mail: avieiraadv@gmail.com

\section{O TRABALHO DECENTE E A SUSTENTABILIDADE: EM BUSCA DE UM RECONHECIMENTO SOCIOAMBIENTAL NO BRASIL}

\author{
THE DECENT WORK AND THE SUSTAINABILITY: IN SEARCH OF
} SOCIO-ENVIRONMENTAL RECOGNITION IN BRAZIL

\section{Patricia Grazziotin Noschang* Anaterra Vieira **}

Como citar: NOSCHANG, Patricia Grazziotin; VIEIRA, Anaterra. O trabalho decente e a sustentabilidade: em busca de um reconhecimento socioambiental no Brasil. Revista do Direito Público, Londrina, v. 16, n. 2, p. 90-103, ago. 2021. DOI 10.5433/24157-108104-1.2021v16n 2p. 90. ISSN: 1980-511X

Resumo: O trabalho decente, agenda promovida pela Organização Internacional do Trabalho desde o ano de 1999, objetiva, sobretudo, viabilizar a garantia de condições mínimas a todos os trabalhadores, em consonância com os objetivos estratégicos da instituição. $O$ presente artigo intenta comprovar a existência de relação entre os dois conceitos: sustentabilidade e trabalho decente, demonstrando sua ligação intrínseca e, por fim, destacar a importância do primeiro para a viabilização do segundo. A problemática enfrentada consiste em apontar a relação entre os dois conceitos e a influência do trabalho decente na construção da sustentabilidade buscando o reconhecimento de uma política socioambiental no Brasil. Apresentam-se, para isso, as definições e os principais aspectos relativos às duas esferas e a interligação entre elas. Para tanto, utiliza-se de método de abordagem dedutivo e de procedimento bibliográfico, a partir de fontes doutrinárias, legislativas e jurisprudenciais. Conclui-se que a preservação do meio ambiente revela-se indispensável para a construção do trabalho decente e sustentável.

Palavras-chave: Socioambiental; Sustentabilidade; Trabalhado decente.

Abstract: Decent work, an agenda promoted by the International Labor Organization since 1999, aims, above all, to guarantee minimum conditions for all workers, in line with the strategic objectives of the institution. This article attempts to prove the existence of a relationship between the two concepts: sustainability and decent work, demonstrating their intrinsic connection and, finally, highlighting the importance of the former for 
the viability of the latter. The problem faced consists of pointing out the relationship between the two concepts and the influence of decent work in the construction of sustainability seeking the recognition of a socio-environmental policy in Brazil. To this end, the deductive approach and bibliographical procedure are used, based on doctrinaire, legislative, and jurisprudential sources. The conclusion is that the preservation of the environment is indispensable for the construction of decent and sustainable work.

Keywords: Social-environmental; Sustainability; Work decent. 


\section{INTRODUÇÃO}

O Direito, enquanto ciência social, encontra-se em constante evolução. Suas variadas ramificações interligam-se com frequência e analisá-las e compreendê-las sob o viés da convergência consiste em tarefa complexa. Essa relação manifesta-se, também, nas medidas e nas políticas adotadas, a fim de conduzi-los, na realidade prática, à concretização dos direitos previstos em cada um dos diversos ramos jurídico.

Esse fenômeno verifica-se, de modo significativo, nas searas do direito do trabalho e do direito ambiental; mais do que isso, há uma relação intrínseca entre o mundo do trabalho e o meio ambiente em sentido amplo.

O que se aborda no âmbito deste artigo é a existência de relação entre a agenda do trabalho decente, promovida pela Organização Internacional do Trabalho (OIT) e a ideia de sustentabilidade enquanto objetivo a ser alcançado no que tange ao desenvolvimento da sociedade. Além disso, intenta-se demonstrar a relevância da agenda do trabalho decente para a construção de uma sociedade sustentável.

A análise acerca da existência dessa relação ocorre por meio do estudo de ambos os conceitos e da forma como suas ideias interligam-se, com o estabelecimento de uma relação na qual se perceba a existência de impactos e de influência recíprocos.

No âmbito trabalhista, constata-se uma série de regramentos, recomendações e normatizações promovidas, em grande parte, pela OIT, que, em consonância com a legislação constitucional e com as regras infraconstitucionais, atuem de modo a viabilizar o acesso de todos os trabalhadores a seus direitos básicos e às garantias fundamentais.

Dentre os mecanismos promotores das garantias das quais devem dispor todos os trabalhadores, destaca-se, no contexto internacional, aquele conhecido como "trabalho decente", que consiste em uma agenda desenvolvida pela OIT e propagada por meio da adoção de políticas públicas por parte de seus Estados-membros. Embora seus fundamentos remetam a direitos e a garantias que consistem em "bandeiras" da instituição, o trabalho decente pode ser compreendido como uma proposta recente.

A relevância da agenda do trabalho decente é bastante clara, e uma breve análise acerca de seus preceitos norteadores permite a constatação de seu caráter indispensável e de sua imprescindibilidade à viabilização de melhores condições de trabalho e de vida a todos os trabalhadores, de quaisquer setores.

Os problemas existentes no mundo do trabalho, aos quais os indivíduos são expostos diariamente, não se restringem à seara laboral, e, por esse motivo, a implementação do trabalho decente como meio apto a repará-los exerce influência sobre a agenda do desenvolvimento sustentável e, consequentemente, sobre a sustentabilidade enquanto objetivo comum às diversas nações que compõem a organização.

A complexidade verificada no conceito de sustentabilidade conduz ao fato de que sua análise consista em um desafio, na medida em que engloba uma série de aspectos distintos e, ao mesmo 
tempo, correlacionados, atinentes à seara ecológica e à esfera socioambiental. Pode ser encarada a partir de diversos ângulos, com a constatação de que, em todos eles, encontram-se fatores humanos e ambientais, indissociáveis e indispensáveis à compreensão da real significação do aludido tema.

Utiliza-se, para tanto, da pesquisa bibliográfica, por meio de análise de doutrina especializada, de artigos jurídico-científicos com enfoque no tema desenvolvido e de jurisprudência referente aos assuntos abordados. O método de abordagem é o dedutivo.

\section{OS OBJETIVOS E OS FUNDAMENTOS DO TRABALHO DECENTE}

A OIT, enquanto organismo especializado da Organização das Nações Unidas (ONU) que visa à promoção dos direitos sociais e da proteção ao trabalho, tem como missão desenvolver ações e agendas que oportunizem melhorias no mundo laboral (SILVA, 2009). Dentre elas, encontra-se a agenda do trabalho decente, solenizada pela OIT no ano de 1999. A agenda do trabalho decente está dentre as prioridades da instituição, considerando seus objetivos estratégicos relacionados ao desenvolvimento social e sustentável (OTI, [2018?]).

Essa proposta insere-se, de modo direto, no verdadeiro compromisso assumido pela OIT no sentido de promover melhores condições de trabalho a todos os homens e a todas as mulheres (OIT, [2018?]). Isso pressupõe a garantia de que recebam remuneração justa e adequada e de que disponham das condições de segurança necessárias para o exercício de suas atividades da melhor maneira possível, de modo que, a partir dela, possam prover o sustento de suas famílias e viver de forma digna.

A partir dessa definição, em aspecto amplo, a agenda do trabalho decente objetiva viabilizar a expansão dos preceitos democráticos, contribuir com a eliminação da miséria, agir de modo a suprimir ou, ao menos, reduzir tanto quanto possível as disparidades sociais e, desse modo, oportunizar o desenvolvimento sustentável (OIT, [2018?]).

$\mathrm{O}$ trabalho decente fundamenta-se, essencialmente, na salvaguarda aos direitos mínimos dos trabalhadores, sob a égide do princípio da dignidade humana. Da mesma forma, objetiva assegurar a inclusão social daqueles que se encontram em situação de fragilidade, proporcionando-lhes o acesso ao emprego adequadamente remunerado, a partir do qual possam realizar suas atividades em condições justas e, assim, viver de maneira digna (BARROS; SILVEIRA; DINIZ, 2016, p. 199-221).

A preconização do referido conceito ocorreu durante a $87^{\mathrm{a}}$ Conferência Internacional do Trabalho, realizada em junho de 1999, ocasião em que o Diretor Geral da instituição, o diplomata chileno Juan Somavia, apresentou-o como o trabalho adequadamente remunerado, em condições justas, sob a égide da equidade, da segurança e da liberdade e, consequentemente, apto a propiciar ao trabalhador a manutenção de uma vida digna e saudável (JACQUES; ORCHARD, 2013, p. 2).

Logo após alcançar o posto de Diretor Geral da OIT, Juan Somavia trouxe à pauta uma disposição inovadora, utilizando-se da expressão "decent work" como forma de definir uma série de objetivos a serem adotados pela instituição a partir daquele momento, considerando o contexto 
internacional no que tange às condições de trabalho frente ao desenvolvimento e à globalização.

O conceito, portanto, mostrou-se como um verdadeiro sintetizador, capaz de, ainda que dotado de caráter amplo, reunir importantes diretrizes e propósitos da OIT, em atenção à situação atinente ao mundo do trabalho e ao desenvolvimento socioeconômico (JACQUES; ORCHARD, 2013, p. 2).

A expressão agrega, em sua definição, aspectos diretamente relacionados aos quatro objetivos estratégicos estabelecidos pela OIT: o respeito aos direitos no trabalho, especialmente àqueles definidos como fundamentais ${ }^{1}$, a promoção do emprego produtivo e de qualidade, a ampliação da proteção social e o fortalecimento do diálogo social (OIT, [2018?]).

Para que atinja as metas que ensejaram sua proposição, o trabalho decente fundamenta-se em quatro objetivos primordiais: a plena observância aos princípios basilares do direito do trabalho, por meio das convenções internacionais da organização, a viabilização de políticas públicas que promovam o emprego devidamente remunerado, a efetivação e a ampliação da proteção social e, também, a expansão da conversação entre os membros do mundo do trabalho (AMORIM; SARSUR; FISCHER, 2010, p. 417-433).

A promoção do trabalho decente interliga-se, de modo direto, a uma estruturação de metas estabelecidas pela ONU no que tange à busca pela viabilização do desenvolvimento sustentável, dentre as quais se destaca o Objetivo de Desenvolvimento Sustentável (ODS) $n^{\circ} 8$, que associa o trabalho decente ao desenvolvimento econômico. A partir desse entendimento, pode-se compreender que a Organização intenta promover a evolução econômica atrelada à sustentabilidade, por meio dos princípios de inclusão, de garantia de emprego pleno e de trabalho decente para homens e para mulheres de todo o mundo (ONU, [2018?]).

O trabalho decente tem de, necessariamente, atentar para o aspecto humano, intrínseco ao mundo laboral, razão pela qual se constata uma genuína relação entre o trabalhador, o contexto no qual este se encontra inserido e o meio ambiente em sentido amplo.

Sua aplicabilidade pode ser verificada em programas desenvolvidos por organismos internacionais como o "Empregos Verdes", que será objeto de apresentação no item "4". Além disso, constata-se sua utilização como fundamento relativo à agendas internas da própria Justiça do Trabalho, como o Ato Conjunto ${ }^{\circ}$ 25/2014, também abordado no mencionado item.

\section{A AGENDA DO TRABALHO DECENTE E SUA IMPORTÂNCIA NA PROMOÇÃO DA SUSTENTABILIDADE}

A promoção do trabalho decente e a obtenção, por meio dele, de resultados positivos na construção da sustentabilidade pressupõem o cuidado relacionado ao meio ambiente em que os seres humanos realizam suas atividades laborais.

1 De acordo com definição constante no site da OIT Brasil, a liberdade sindical, o direito à negociação coletiva, a eliminação de todas as formas de discriminação em matéria de emprego a erradicação de todas as formas de trabalho forçado e de trabalho infantil são considerados objetivos fundamentais a serem promovidos pela organização (OIT, [2015?]). 
No que diz respeito à aludida garantia, tem-se como imprescindível que se busque a plena observância ao princípio da dignidade humana, por meio, dentre outros, do fundamento do trabalho decente, que atua como instrumento protetivo destinado a assegurar condições mínimas de saúde, segurança e dos demais direitos básicos do trabalhador (BARROS; SILVEIRA; DINIZ, 2016, p. 199-221).

No Brasil, o direito ao meio ambiente de trabalho decente encontra sua previsão na Constituição Federal da República Federativa do Brasil (CFRB), uma vez que a disposição referente à saúde e à segurança do trabalhador apresenta-se como o verdadeiro âmago do regramento trazido por seu artigo $7^{\circ}$, inciso XXII (BARROS; SILVEIRA; DINIZ, 2016, p. 199-221). A partir da compreensão do direito ao meio ambiente de trabalho saudável como um verdadeiro direito fundamental, assegurado pela legislação interna, vislumbra-se o dever de que o Estado atue no sentido de concretizá-lo e de expandi-lo até que todos os seus destinatários sejam por ele alcançados (FARIAS, 2017, p. 443-462).

O direito ao meio ambiente de trabalho saudável não se refere apenas àqueles trabalhadores inseridos em vínculos empregatícios; estende-se, por óbvio, a todos os que exercem atividade laborativa, ainda que em condição de informalidade (FARIAS, 2017, p. 443-462). Trata-se, desse modo, de direito de caráter essencial, previsto no ordenamento jurídico pátrio e aplicável à integralidade dos indivíduos.

Essa garantia é indispensável à manutenção de uma vida digna por parte de cada trabalhador, independentemente da área de atuação ou da modalidade de exercício das atividades profissionais. Transcende, assim, à delimitação de direito trabalhista e é assumido como um verdadeiro direito fundamental, inerente à totalidade dos seres humanos. Tem-se, pois, que todo e qualquer indivíduo, no exercício de seu ofício, deve dispor da salvaguarda ao meio ambiente de trabalho sadio e decente (CAMILO, 2015, p. 51-71).

O meio ambiente laboral encontra-se inserido no conceito lato sensu de meio ambiente, razão pela qual suas alterações e seus desequilíbrios reverberam em problemas extensivos, como uma verdadeira agressão não apenas aos direitos sociais mas, também, aos direitos transindividuais (CAMILO, 2015, p. 51-71).

A partir desse entendimento, não há como compreender e solucionar quaisquer problemas relativos à degradação ambiental, em largo espectro, sem atentar para as condições de trabalho às quais os indivíduos encontram-se expostos, uma vez que dizem respeito a uma intrínseca relação entre os seres humanos e o meio ambiente, tanto no aspecto natural quanto no aspecto social.

Há uma corrente de sociólogos que reconhece a existência de uma relação efetiva entre a equidade social e a sustentabilidade, embasada na premissa de que os aspectos que caracterizam a desigualdade correlacionam-se, também, à degradação do meio ambiente. Esse entendimento permite a compreensão de que a aludida relação trata-se de um verdadeiro mecanismo de retroalimentação, em que se verifica a ocorrência de relação de "causa e efeito" de forma cíclica e contínua. (RATTNER, 1999, p. 235).

A partir dessa ideia, o desgaste do meio ambiente enseja a manutenção da situação de vul- 
nerabilidade humana, ao mesmo tempo em que o ser humano, exposto ao ambiente degradado, tende a permanecer impossibilitado de modificá-lo ou, ainda, a acabar degradando-o com mais intensidade (RATTNER, 1999).

O labor em condições inadequadas e sem a observância às garantias mínimas destinadas à proteção dos indivíduos e do meio em que se encontram inseridos acaba por refletir no desgaste do espaço ambiental e social, e, desse desgaste, de modo reflexo, resulta a precarização do meio ambiente laboral. Configura-se, assim, a correlação entre as circunstâncias laborais e o plano ambiental.

A ideia da promoção de sustentabilidade relacionada ao emprego tem de, necessariamente, atentar para a diminuição dos riscos aos quais os trabalhadores são expostos em ambiente laboral. O trabalho decente, portanto, atua como elemento viabilizador da sustentabilidade laboral, uma vez que sua concepção consiste justamente na propagação e na extensão da proteção ao trabalhador por meio da salvaguarda a seus direitos básicos e fundamentais (BARROS; PADILHA, 2016, p. 75).

À efetivação da sustentabilidade (tanto em sentido estrito, com enfoque ao ambiente laboral, quanto em sentido amplo, no contexto internacional de desenvolvimento), faz-se necessária a promoção da agenda do trabalho decente, sem a qual a construção de avanços genuínos torna-se intangível.

Desse modo, com o objetivo de promover a sustentabilidade ambiental por meio de melhora nas relações de trabalho, a OIT, o Programa das Nações Unidas para o Meio Ambiente (PNUMA) e a Confederação Sindical Internacional (CSI) desenvolveram, no ano de 2007, o programa "Empregos Verdes". O objetivo do programa consiste em fomentar e possibilitar a expansão das oportunidades de emprego em consonância com os cuidados ambientais indispensáveis no panorama atual. A necessidade de gerar empregos verdes surge como uma consequência do princípio da sustentabilidade, bem como do reconhecimento constitucional de que a ordem econômica, que encontra seu fundamento no art. 170, da CF/1988, tem como alicerce a valorização do trabalho humano para promover existência digna, através da preservação do meio ambiente (COMPAGNONI et al., 2012; OLIVEIRA; CECATO, 2016, p. 215).

Importante ressaltar que a relação entre trabalho e meio ambiente começa a ser construída na Conferencia do Rio de Janeiro em 1992. Mas o temas efetivamente se interligam com o objetivo da sustentabilidade em 2007 com a proposta referida do programa "Empregos Verdes", no qual convergem os ideais do PNUMA e da OIT em prol do desenvolvimento sustentável (OIT, 2013, p. 3).

O programa "Empregos Verdes" consiste em uma das mais importantes e abrangentes medidas adotadas pelos organismos internacionais a fim de levar as ideias de garantia ao trabalho decente e de sustentabilidade laboral e ambiental à realidade prática. O referido programa aclara a compreensão de que o trabalho decente e sustentável consiste em um dos pressupostos à concretização de políticas socioambientais efetivas e eficientes em seus propósitos. 


\section{CONECTANDO TRABALHO DECENTE E SUSTENTABILIDADE: DAS POLÍTICAS PÚBLICAS À ATUAÇÃO DA JUSTIÇA DO TRABALHO}

É possível perceber que o conceito de sustentabilidade possui caráter multifacetado. Dentre as definições observadas em âmbito internacional, destaca-se a de Ignacy Sachs, que intenta, de certo modo, fracionar e delimitar o conceito de sustentabilidade, com menção aos critérios social, cultural, ecológico, ambiental, territorial, econômico e político.(SACHS, 2000, p.85-88) A conceituação apresenta espectro múltiplo, a partir da observância de um conjunto de parâmetros que, em consonância, clarificam a ideia acerca do que realmente significa sustentabilidade. Ignacy Sachs também refere-se à sustentabilidade como "conceito dinâmico, que leva em conta as necessidades crescentes da população, num contexto internacional em constante expansão." (SACHS, 1990, p.235-256). Nessa definição é verificada a presença da ideia de movimento, ou seja, de que na sustentabilidade verifica-se uma conceituação sujeita a mudanças e evoluções e, também, do elemento humano como pressuposto intrínseco à sua concretização.

A sustentabilidade, em seus aspectos humano e ambiental, pressupõe a ideia de utilização consciente dos recursos naturais a fim de que a manutenção da vida humana em condições adequadas seja plenamente possível. (MIKHAILOVA, 2004, p. 22-41) Dessa forma, verifica-se a associação entre as ideias de desenvolvimento humano e de preservação ambiental.

A sustentabilidade abarca, em cada um de seus parâmetros, a ligação entre os indivíduos e o ambiente que os cerca. Ao mesmo tempo em que figura como principal responsável pela viabilização de uma sociedade sustentável, o ser humano mostra-se, também, como o principal afetado pelos desequilíbrios ambientais e sociais verificados na contemporaneidade. Não há a possibilidade, portanto, de que se analise a sustentabilidade, a partir de quaisquer de seus enfoques, sem que atente-se para seus aspectos humanos, que constituem, em realidade, seu âmago. Nesse sentido, pois, tem-se a percepção acerca da relevância da adoção de medidas concretas que conectem, na realidade prática, o mundo do trabalho à ideia de sustentabilidade.

Com esse enfoque, o programa "Empregos Verdes" sintetiza a ideia de modificação econômica de empresas, de ambientes de trabalho e de mercados laborais rumo à construção de um modelo econômico sustentável, em que o trabalho decente seja possível a cada um dos trabalhadores (OIT, 2009).

A ideia atinente ao programa "empregos verdes" é constituída de três aspectos conceituais: o aspecto econômico, o aspecto social e o aspecto ambiental. Todos eles, por óbvio, relacionam-se de maneira veemente. A agenda do trabalho decente insere-se no aspecto social e, desse modo, impacta da seara econômica e na seara ambiental. Mais que isso, o emprego verde, segundo a OIT, se traduz por um posto de trabalho que está inserido em um empreendimento eficiente, voltado para um funcionamento preocupado com a preservação do meio ambiente." (OLIVEIRA; CECATO, 2016, p. 214).

A OIT, em seus documentos oficiais, relaciona os empregos verdes ao trabalho decente de modo direto, com o reconhecimento de que a noção de trabalho sustentável somente é possível por 
meio da verificação de que as atividades laborais sejam prestadas em ambiente saudável e atento às normas e aos preceitos de proteção à dignidade humana de todos os trabalhadores (OIT, 2009).

O programa tem-se revelado valoroso e consiste em um grande avanço rumo à expansão da proposta de sustentabilidade em ambiente laboral, atrelada à construção de uma sociedade sustentável.

Os conceitos de trabalho decente e de sustentabilidade precisam, de fato, ser aplicados à realidade prática para que suas consequências positivas sejam verificadas na vida de cada trabalhador e contribuam de forma efetiva na construção da ideia de um mundo sustentável. Para que isso seja possível, tem-se como imprescindível, em consonância com os programas desenvolvidos pelas entidades internacionais, a adoção de medidas direcionadas à sua promoção por parte de entidades especializadas. Nesse âmbito, encontra-se a Justiça do Trabalho enquanto parte integrante do Poder Judiciário.

Nesse contexto, o Conselho Superior da Justiça do Trabalho e o Tribunal Superior do Trabalho (TST) publicaram, em 18 de novembro de 2014, o Ato Conjunto $n^{\circ}$ 25/2014, que dispôs acerca da criação e da instituição da chamada "Política Nacional de Responsabilidade Socioambiental da Justiça do Trabalho". O ato delimita uma série de princípios, objetivos, instrumentos, medidas, diretrizes e políticas a serem adotadas pelos Tribunais Regionais do Trabalho, em atenção às particularidades e circunstâncias específicas de cada região (BRASIL, 2014b).

O aludido ato conjunto estabelece a promoção do valor social do trabalho, da dignificação do trabalhador, da responsabilidade socioambiental e da contribuição ao desenvolvimento sustentável como objetivos atinentes à Política Nacional de Responsabilidade Socioambiental da Justiça do Trabalho, o que demonstra a relevância e a importância do trabalho decente enquanto política por meio da qual se podem alcançar resultados práticos positivos na esfera da proteção aos direitos dos trabalhadores e, também, na construção de uma sociedade plenamente sustentável. A medida refere-se à sustentabilidade e ao trabalho decente como duas de suas principais definições, utilizadas para pautar a adoção de medidas práticas e de políticas necessárias à efetivação de seus objetivos. A sustentabilidade consiste, também, em um de seus princípios. ${ }^{2}$

O envolvimento e o desenvolvimento da comunidade encontram-se previstos pelo artigo 18, inciso VI como uma de suas diretrizes, o que denota o caráter múltiplo e solidário relativo à normatização. Seu intuito principal é, portanto, definir, organizar e levar à prática um conjunto de políticas e medidas afirmativas capazes de promover e de viabilizar a sustentabilidade por meio da proteção aos princípios fundamentais e ao regramento internacional atinente ao trabalho, ao meio ambiente e à dignidade humana.

A implementação do ato no âmbito da Justiça do Trabalho denota a importância da adoção de esforços conjuntos voltados ao trabalho decente, à dignidade do trabalhador e à responsabilidade

2 Artigo $8^{\circ}$ São objetivos da PNRSJT: I - Estabelecer instrumentos e diretrizes de Responsabilidade socioambiental; II - Promover a integração e a efetividade das ações de Responsabilidade socioambiental; III - Promover o valor social do trabalho e a dignificação do trabalhador; IV - Promover a gestão eficiente e eficaz dos recursos sociais, ambientais e econômicos; V - Contribuir para o fortalecimento das políticas públicas voltadas para o desenvolvimento sustentável (BRASIL, 2014b). 
socioambiental no que se refere à concretização de uma sociedade sustentável. Além disso, evidencia a existência de relação intrínseca entre a esfera trabalhista e a esfera ambiental, com enfoque especial ao desenvolvimento sustentável e à sustentabilidade enquanto conceitos em que se verifica a relevância do elemento humano.

A fim de que a implementação de esforços conjuntos em prol da construção de uma sociedade sustentável seja efetivada, é imprescindível que as decisões judiciais voltem-se ao mesmo objetivo. Cabe à Justiça do Trabalho, além de promover políticas conjuntas de promoção de diálogo social e de proposição de melhorias socioambientais, aplicar o regramento internacional e, também, a normatização constitucional aos casos concretos sob sua análise.

É dever do Poder Judiciário e, sobretudo, da Justiça do Trabalho promover o respeito às normas internacionais e constitucionais acerca da dignidade, da segurança e da saúde do trabalhador. Essa promoção dá-se, então, a partir da aplicação do fundamento e trabalho decente, também, aos casos concretos levados à análise do judiciário trabalhista.

O TST é o órgão responsável pela apreciação e pelo julgamento das mais relevantes e significativas demandas relacionadas às relações trabalhistas. Possui, dessa forma, a responsabilidade de unificar a jurisprudência trabalhista em âmbito nacional. Suas decisões possuem especial relevância no que diz respeito à salvaguarda aos direitos trabalhistas e às garantias das quais devem dispor, na prática, todos os trabalhadores e todas as trabalhadoras, independentemente de quais sejam as funções por eles exercidas ou de quais sejam os locais ou as regiões em que prestam seus serviços. Atua, assim, como agente, ligado ao poder público, ao qual incumbem os cuidados e as atenções necessárias à resolução de conflitos que envolvam os atores do mundo do trabalho.

No ordenamento jurídico brasileiro, muitas são as decisões que abarcam o conceito de trabalho decente, promovendo-os por meio de sua aplicação a casos concretos analisados pelo Poder Judiciário. Essas ações, genuinamente importantes, trazem à realidade, por meio da aplicação das determinações legais, a efetividade de determinações oriundas da entidade mais importante no que se refere à promoção da proteção ao trabalho, em todas as suas formas.

Nesse sentido, o TST, no julgamento do Recurso de Revista n 75700-37-2010-5-16-0009, decidiu por dar provimento à ação civil pública, proposta pelo Ministério Público do Trabalho, que objetivou a determinação de que o Poder Público proceda, por meio de condenação em obrigação de fazer e de não fazer, à adoção de políticas, a fim de erradicar o trabalho infantil, que consiste em um dos mais graves problemas relacionados ao mundo do trabalho e, consequentemente, à busca por uma sociedade sustentável, principalmente em seu aspecto socioambiental (BRASIL, 2013).

A decisão menciona o trabalho decente como um de seus fundamentos. Baseia-se, também, no regramento internacional de proteção à pessoa humana, na Convenção $n^{\circ} 182$ da OIT e no regramento constitucional de proteção ao trabalho e à criança e ao adolescente. Mostra-se de grande relevância, uma vez que denota a importância da atuação da Justiça do Trabalho a fim de garantir a observância às normas internacionais e, mais do que isso, sua efetivação nas relações de trabalho.

Decisões judiciais consistem em um dos meios pelos quais se torna possível atingir a me- 
lhora nas relações trabalhistas, no ambiente em que elas se desenvolvem e, consequentemente, no meio ambiente em sentido amplo, com a promoção da sustentabilidade enquanto objetivo da justiça especializada na resolução de conflitos trabalhistas.

O trabalho, enquanto valor social protegido pelo regramento internacional e, também, pela norma interna, possui cunho fundamental. Por esse motivo, sua proteção consiste em dever do poder público como um todo. Sua relação com a sustentabilidade dá-se, pois, de maneira intrínseca, uma vez que os desequilíbrios verificados na seara laboral afetam, por óbvio, àqueles que nele se inserem e o meio ambiente em sentido amplo. Nele, todos os seres humanos figuram como principais geradores de impacto e, ao mesmo tempo, como vítimas da degradação que ocasionam.

As políticas de salvaguarda ao trabalho e de preservação ambiental mostram-se genuinamente importantes e possibilitam que a sustentabilidade passe a ser viável e tangível à realidade concreta. A ideia de vida sustentável somente pode ser considerada acessível com o trabalho decente, em condições mínimas e atento às garantias individuais e sociais das quais devem dispor todos os trabalhadores, independentemente de quaisquer diferenças existentes entre eles.

As iniciativas promovidas pelos organismos internacionais, o regramento interno dos Estados-membros desses organismos, as ações e as políticas públicas promovidas pelo poder público e a aplicação de todos esses conceitos e de todas essas normatizações por parte do Poder Judiciário constituem um meio para que se obtenham os resultados necessários à construção de uma sociedade sustentável, com atenção especial ao elemento humano.

A ideia de vida sustentável somente pode ser considerada viável com o trabalho decente, em condições mínimas e atento às garantias individuais e sociais das quais devem dispor todos os trabalhadores, independentemente de quaisquer diferenças existentes entre eles.

\section{CONCLUSÃO}

O trabalho decente, em todos os seus aspectos, resulta em reflexos benéficos à sustentabilidade em sentido amplo. Sua não observância, então, ocasiona impactos negativos à efetivação do desenvolvimento sustentável e à construção da sustentabilidade enquanto objetivo global.

Muitos são os pontos de convergência entre as duas ideias, e a análise dessa relação consiste em objeto de diversos estudos, de suma relevância à compreensão da sociedade como um todo, de seus rumos e das adaptações e nos avanços necessários à sua manutenção.

O meio ambiente de trabalho degradado engloba o trabalhador exposto a condições indignas, a natureza dizimada pela ação humana e a impossibilidade de que o indivíduo a ele exposto seja retirado desse contexto de destruição ambiental e social sem que, para isso, sejam realizados esforços conjuntos. É a partir dessa constatação que se verifica a indispensabilidade da agenda do trabalho decente.

A sustentabilidade pode ser compreendida a partir de variados enfoques. Contudo, o ele- 
mento humano é verificado em cada um deles, uma vez que o ser humano, ao mesmo tempo em que é o grande causador dos desequilíbrios sociais e da degradação ambiental, encontra-se em uma posição na qual acaba por ser atingido por todos esses impactos.

A promoção do trabalho decente associa-se de maneira significativa à busca e aos esforços pela viabilização de uma sociedade sustentável, tanto no que diz respeito ao meio ambiente enquanto natureza quanto no que tange ao meio ambiente em sentido amplo, no qual os seres humanos encontram-se inseridos. Isso significa que tanto a degradação ambiental quanto a vulnerabilidade econômica impossibilitam a construção de uma sociedade sustentável, e, mais ainda, ambas as mazelas coexistem em decorrência uma da outra.

Com a garantia de um ambiente saudável é possível buscar implementar no Brasil politicas socioambientais principalmente tomando como base as decisões acima apresentada que já indicam um reconhecimento desta propostas.

É implausível conhecer e entender os aspectos relevantes referentes ao mundo do trabalho sem, antes disso, adentrar em questões atinentes ao meio ambiente e à sustentabilidade, questões de significativa relevância no panorama atual.

Assim promoção de ações conjuntas e a atuação do poder público e dos organismos especializados às diversas áreas relacionadas à proteção aos valores do trabalho e à sustentabilidade consistem em mecanismos por meio dos quais a busca por uma sociedade sustentável mostra-se possível.

Há que se visar ao desenvolvimento equilibrado, a fim de alcançar o objetivo representado pela sustentabilidade por meio, dentre outros, da promoção ao trabalho digno, atento às garantias fundamentais e extensivo à totalidade dos trabalhadores. Sem isso, a sustentabilidade torna-se uma ideia inatingível à realidade fática.

\section{REFERÊNCIAS}

AMORIM, Wilson Aparecido Costa de; SARSUR, Amyra Moyzés; FISCHER, André Luiz. Trabalho decente, ética e liberdade. Revista de Ciências Humanas, Florianópolis, v. 44, n. 2, p. 417-433, out. 2010.

BARROS, Marina Dorileo; SILVEIRA, Paula Galbiatti; DINIZ, Bismarck Duarte. Trabalho decente atrelado à preservação ambiental: Análise do programa Empregos Verdes. Veredas do Direito, Belo Horizonte, v. 13, n. 25, p. 199-221, jan./abr. 2016.

BARROS, Veronica Altef; PADILHA, Norma Sueli. Construção sustentável e meio ambiente do trabalho. Revista do Direito do Trabalho e Meio Ambiente do Trabalho, Curitiba, v. 2, n. 2, p. 58-78, jul./dez. 2016.

BRASIL. Tribunal Superior do Trabalho . Recurso de Revista 757003720105160009. Recurso de revista. Ação civil pública. Competência da justiça do trabalho. Efetivação de princípios e regras constitucionais e internacionais ratificados, relativos à pessoa humana e às relações de trabalho. Trabalho decente $\mathrm{e}$ 
combate imediato e prioritário ao trabalho infantil e às piores formas de trabalho do adolescente. Relator: Min. Mauricio Godinho Delgado, 17 de setembro de 2013. Publicação: DEJT 20/09/2013. Disponível em: https://tst.jusbrasil.com.br/jurisprudencia/24192460/recurso-de-revista-rr-757003720105160009-757003720105160009-tst. Acesso em: Acesso em: 15 ago. 2018.

BRASIL. Tribunal Superior do Trabalho. Ato conjunto CSJT.TST.GP n ${ }^{0}$ 24, de 13 de novembro de 2014. Institui a Política Nacional de Responsabilidade Socioambiental da Justiça do Trabalho - PNRSJT. Brasília: Conselho Superior da Justiça do Trabalho , 2014b. Disponível em: https:/juslaboris.tst.jus.br/ bitstream/handle/20.500.12178/52380/2014_atc0024_tst_csjt_atu alizado.pdf? sequence $=1$ \&isAllowed $=\mathrm{y}$. Acesso em: 15 ago. 2018.

CAMILO, Adélia Procópio. Meio ambiente do trabalho como direito fundamental e responsabilidade civil do empregador. Revista de Direito do Trabalho e Meio Ambiente do Trabalho, Minas Gerais, v. 1, n. 2, p. 51-71, jul./dez. 2015.

COMPAGNONI, Rudimar; CHEMIN, Beatris Francisca; TURATTI, Luciana; CALDERAN, Thanabi Bellenzier; KONRAD, Odorico. Empregos verdes como mecanismo de redução de impactos ambientais. Âmbito Jurídico, Rio Grande, v. 15, n. 106, nov. 2012. Disponivel em: http://www.ambitojuridico.com. br/site/index.php/index.php?n_link=revista_artigos_leitura\&arti go_id $=12423 \&$ revista_caderno $=5$. Acesso em: 20 jul. 2018.

FARIAS, Talden Queiroz. Meio ambiente do trabalho. Revista Direito e Liberdade, Mossoró, v. 6, n. 2, p. 443-462, jan.jun. 2017.

JACQUES, Caroline da Graça; ORCHARD, Maria Soledad Etcheverry. Trabalho decente e dignidade do trabalhador na agenda política do sindicalismo brasileiro. Avanços de investigação em curso. In: CONGRESSO DAASSOCIAÇÃO LATINOAMERICANA DE SOCIOLOGIA, 24, 2013, São Paulo. Anais [...]. São Paulo, 2013. Disponível em: http://actacientifica.servicioit.cl/dir.php?archivo=18. Acesso em: 22 jul. 2018.

MIKHAILOVA, Irina. Sustentabilidade: evolução dos conceitos teóricos e os problemas da mensuração prática. Revista Economia e Desenvolvimento, Santa Maria, n. 16, p. 22-41. 2004.

OLIVEIRA, Flavia de Paiva Medeiros de; CECATO, Maria Aurea Baroni. Trabalho decente e emprego verde: uma análise à luz do caráter pluridimensional da sustentabilidade. Revista de Direito e Sustentabilidade, Curitiba, v. 2, n. 2, p. 207-225, jul/dez. 2016.

ONU - ORGANIZAÇÃO DAS NAÇÕES UNIDAS. Objetivo 8: promover o crescimento econômico sustentado, inclusivo e sustentável, emprego pleno e produtivo e trabalho decente para todas e todos. Brasília: ONU, [2018?]. Disponível em: https://nacoesunidas.org/pos2015/ods8/. Acesso em: 12 jun. 2018.

OTI - ORGANIZAÇÃO INTERNACIONAL DO TRABALHO. Conheça a OIT. Brasília: OTI, [2015?]. Disponível em: https://www.ilo.org/brasilia/conheca-a-oit/lang--pt/index.htmhttps://nacoesunidas. 
org/pos2015/ods8/. Acesso em: 12 jun. 2018 .

OTI - ORGANIZAÇÃO INTERNACIONAL DO TRABALHO. Desenvolvimento sustentável, trabalho digno e empregos verdes. Genebra: Bureau Internacional do Trabalho, 2013. Relatório V. Disponível em: https:/www.ilo.org/wcmsp5/groups/public/---europe/---ro-geneva/---ilo-lisbon/documents/genericdocument/wcms_665179.pdf. Acesso em: 20 maio 2020.

OTI - ORGANIZAÇÃO INTERNACIONAL DO TRABALHO. Programa empregos verdes. Brasília: OTI, 2009. Disponível em: https:/www.ilo.org/brasilia/publicacoes/ WCMS_229629/lang--pt/index.htm. Acesso em: 18 abr. 2019.

OTI - ORGANIZAÇÃO INTERNACIONAL DO TRABALHO. Trabalho decente. Brasília: OTI, [2018]. Disponível em: https://www.ilo.org/brasilia/temas/trabalho-decente/lang--pt/index. htm. Acesso em: 22 jun. 2018.

RATTNET, Henrique. Sustentabilidade: uma visão humanista. Ambiente \& Sociedade, Campinas, n. 5, jul./dez. 1999.

SACHS, Ignacy. Caminhos para o desenvolvimento sustentável. 1. ed. Rio de Janeiro: Garamond, 2000.

SACHS, Ignacy. Desarrollo sustentable, bio-industrialización descentralizada y nuevas configuraciones rural-urbanas. Los casos de India y Brasil. Pensamiento Iberoamericano, Madrid, v. 46, 1990.

SILVA, Guilherme Oliveira Catanho da. Aplicabilidade das Convenções da OIT na Prática Trabalhista. E-Gov, 2009. Disponível em: www.egov.ufsc.br/portal/sites/default/files/anexos/32200- 8299-1-PB. pdf. Acesso em: 25 jul. 2018.

Como citar: NOSCHANG, Patricia Grazziotin; VIEIRA, Anaterra. O trabalho decente e a sustentabilidade: em busca de um reconhecimento socioambiental no Brasil. Revista do Direito Público, Londrina, v. 16, n. 2, p. 90-103, ago. 2021. DOI 10.5433/24157-108104-1.2021v16n2p. 90. ISSN: 1980-511X

Recebido em: 29/10/2019

Aprovado em: 17/08/2020 